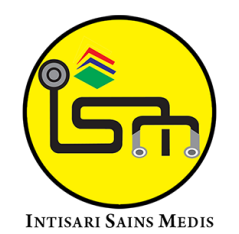

Published by Intisari Sains Medis

\section{Klasifikasi, diagnosis, dan pengobatan saat ini untuk penyakit mata kering: tinjauan pustaka}

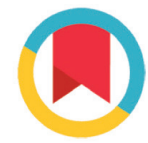

CrossMark

Anthea Casey $^{1 *}$, Sari Marina ${ }^{1}$

\section{ABSTRACT}

Background: Dry eye disease (DED) is one of the most prevalent ocular diseases in the world. In Indonesia, lifestyles driven by information technology have brought DED a severe public health concern. Affected individuals usually come with varied symptoms, such as photophobia, fatigue, itchiness, burning sensation, irritation, and visual disturbance. The aim of this study is to provide a review of the current classification, diagnosis, and treatment for dry eye disease.

Method: We conducted a literature review using Pubmed, Proquest, and Google Scholar databases. Relevant articles from 2015 to 2021 were collected and analyzed based on the results of previous studies. Result: According to the Asia Dry Eye Society (ADES) report in 2020, DED is classified into three types: aqueous-deficient, decreased wettability, and increased evaporation. This classification is based on the concept of tear film-oriented diagnosis and respectively coincide with the problem of each layer: aqueous, membrane-associated mucins, and lipid/ secretory mucin. A practical diagnostic tool based on the fluorescein breakup patterns (FBUP) is recommended to differentiate the type of DED and, furthermore, help to select the choices of treatment.

Conclusion: This classification proposed by ADES is simple to use through use of fluorescein, which is available even to non-dry eye specialists, and which hopefully contribute to an effective diagnosis and treatment for dry eye disease.

Keywords: Dry eye, tear film, fluorescein breakup pattern, tear film-oriented diagnosis, tear film-oriented therapy. Cite This Article: Casey, A., Marina, S. 2021. Klasifikasi, diagnosis, dan pengobatan saat ini untuk penyakit mata kering: tinjauan pustaka. Intisari Sains Medis 12(2): 640-644. D0I: 10.15562/ism.v12i2.998

\title{
ABSTRAK
}

Latar Belakang: Penyakit mata kering (dry eye disease/DED) merupakan salah satu penyakit mata tersering di dunia. Di Indonesia, seiring dengan kemajuan teknologi informatika, DED menjadi masalah kesehatan yang serius. Pasien umumnya datang dengan keluhan yang bervariasi, seperti fotofobia, mata lelah, gatal, terasa panas atau terbakar, iritasi, dan gangguan penglihatan. Tujuan dari tinjauan pustaka ini adalah memberikan ulasan mengenai klasifikasi, diagnosis, dan tatalaksana mata kering saat ini.

Metode: Sumber pustaka diperoleh dari database Pubmed, Proquest, dan Google Scholar. Artikel-artikel yang relevan yang dipublikasi dalam rentang waktu tahun 2015 sampai 2021 dikumpulkan dan dianalisis berdasarkan hasil dari penelitian sebelumnya.

Hasil: Berdasarkan laporan Asia Dry Eye Society (ADES) di tahun 2020, DED diklasifikasikan menjadi tiga tipe, yaitu defisiensi aqueous, penurunan keterbasahan, dan peningkatan evaporasi. Klasifikasi ini didasarkan pada konsep tear film-oriented diagnosis (TFOD) di mana ketiga tipe ini sesuai dengan letak lapisan air mata yang mengalami kelainan, yaitu lapisan aqueous, membrane-associated mucins, dan lipid/secretory mucin. Diagnosis tipe DED dapat dilakukan dengan pemeriksaan fluorescein breakup pattern (FBUP) yang kemudian hal ini akan membantu dalam menentukan tatalaksana yang sesuai untuk penyakit mata kering. Simpulan: Klasifikasi DED oleh ADES ini mudah dan praktis digunakan, hanya dengan menggunakan fluoresein. Hal ini diharapkan dapat membantu menegakkan diagnosis yang efektif dan tatalaksana penyakit mata kering bahkan bagi dokter non-spesialis penyakit mata kering.
Anthea Casey;

Bagian Mata RSUD Bali Mandara, Denpasar, Bali, Indonesia;

antheacasey@yahoo.co.id
Kata kunci: Mata kering, tear film, fluorescein breakup pattern, tear film-oriented diagnosis, tear film-oriented therapy.

Sitasi Artikel ini: Casey, A., Marina, S. 2021. Klasifikasi, diagnosis, dan pengobatan saat ini untuk penyakit mata kering: tinjauan pustaka. Intisari Sains Medis 12(2): 640-644. D0I: 10.15562/ism.v12i2.998 


\section{PENDAHULUAN}

Penyakit matakering (dryeyedisease/DED) merupakan salah satu penyakit mata yang sering ditemui dalam praktik sehari-hari. Pasien umumnya memiliki keluhan yang bervariasi, seperti fotofobia, mata lelah, gatal, terasa panas atau terbakar, iritasi, dan gangguan penglihatan. Keluhankeluhan ini dapat mengganggu aktivitas sehari-hari dan menurunkan kualitas hidup seseorang karena sifatnya yang kronis dan membutuhkan terapi jangka panjang. Tidak jarang pasien dengan penyakit mata kering juga disertai dengan gejala depresi dan gangguan mood. ${ }^{1}$

DED merupakan penyakit multifaktorial yang berhubungan dengan ketidakstabilan lapisan air mata, hiperosmolaritas, inflamasi, dan abnormalitas neurosensori. ${ }^{2}$ Pada tahun 2017, Asia Dry Eye Society (ADES) menekankan ketidakstabilan lapisan air mata sebagai etiologi utama dari DED dan pada tahun 2020 mengklasifikasikan DED menjadi tiga, yaitu defisiensi aqueous, peningkatan evaporasi, dan penurunan keterbasahan kornea, dan konjungtiva. ${ }^{3,4}$

Studi epidemiologi menunjukkan bahwa prevalensi DED dengan atau tanpa gejala mata kering berkisar antara 5-50\%. Prevalensi DED di negara-negara Asia Tenggara menunjukkan angka yang cukup tinggi, yaitu sebesar 20-52,4\% dibandingkan dengan negara-negara di Eropa (Spanyol 18,4\%, Inggris 20\%) dan Amerika (14,5\%). ${ }^{5}$ Sebagian besar studi menunjukkan bahwa prevalensi DED pada perempuan 1,33-1,74 kali lebih tinggi dibandingkan dengan laki-laki dan meningkat seiring dengan usia (puncaknya pada usia 40-50 tahun). ${ }^{5,6}$ Seiring dengan kemajuan teknologi informatika, DED menjadi masalah kesehatan yang serius. Penggunaan komputer atau gadget akan berdampak pada turunnya refleks berkedip yang kemudian menyebabkan peningkatan evaporasi pada mata. ${ }^{7}$ Selain usia tua, jenis kelamin perempuan, dan ras Asia, beberapa faktor risiko DED lainnya adalah disfungsi kelenjar Meibom, sindrom Sjogren, defisiensi hormon androgen, terapi hormon estrogen, penyakit jaringan ikat, pengguna komputer dan lensa kontak, lingkungan (angin, polusi, humiditas rendah), serta obat-obatan (antihistamin, antidepresan, ansiolitik, dan isotretinoin). ${ }^{1,5}$

Pada tinjauan pustaka ini akan dibahas mengenai klasifikasi, diagnosis, dan tatalaksana mata kering yang diharapkan dapat memudahkan klinisi dalam menegakkan diagnosis dan pemberian terapi.

\section{METODE}

Metode penulisan yang digunakan adalah tinjauan pustaka. Sumber kepustakaan diperoleh dari database Pubmed, Proquest, dan Google Scholar dengan menggunakan kata kunci "dry eye", "tear", "fluorescein breakup pattern", "tear film-oriented diagnosis", dan "tear film-oriented therapy". Literatur yang dipilih adalah literatur yang dipublikasikan tahun 2015 sampai 2021, yang relevan dengan penyakit mata kering, dan sesuai dengan kata kunci. Literatur yang dipublikasikan di luar rentang waktu yang telah disebutkan tidak dimasukkan ke dalam tinjauan pustaka. Literatur-literatur yang dipilih kemudian dikumpulkan dan dianalisis berdasarkan hasil dari penelitian sebelumnya lalu disusun menjadi satu kajian literatur ilmiah.

\section{HASIL}

\section{Definisi dan klasifikasi}

Dry eye disease (DED) atau penyakit mata kering didefinisikan sebagai penyakit multifaktorial yang ditandai dengan hilangnya homeostasis air mata, dan disertai oleh gejala di mata, di mana ketidakstabilan lapisan air mata, hiperosmolaritas, inflamasi, dan abnormalitas neurosensori memiliki peran penting. Tear Film and Ocular Surface Society Dry Eye Workshop II (TFOS DEWS II) mengklasifikasikan DED menjadi dua tipe, yaitu aqueous deficient dry eye (ADDE) dan evaporative dryeye (EDE). ${ }^{2} \mathrm{ADDE}$ merupakan kondisi yang berkaitan dengan kegagalan fungsi kelenjar lakrimal untuk menghasilkan komponen aqueous yang adekuat sehingga terjadi kerusakan permukaan mata (kornea dan konjungtiva). Penyakit mata kering tipe ini sering ditemui pada pasien dengan sindrom Sjogren, graft versus host disease (GVHD), ocular cicatricial pemphigoid (OCP) dan sindrom StevenJohnson. Sementara itu, EDE berkaitan dengan peningkatan evaporasi air mata yang sering terjadi pada disfungsi kelenjar Meibom/Meibom gland dysfunction (MGD), blink-related (contoh pada lagoftalmos atau pengguna gadget), dan pengguna lensa kontak. ${ }^{2-4}$

Pada tahun 2017, Asia Dry Eye Society (ADES) mendefinisikan DED sebagai penyakit multifaktorial yang ditandai dengan ketidakstabilan lapisan air mata yang menyebabkan serangkaian gejala dan/atau gangguan penglihatan, yang berpotensi menyebabkan kerusakan permukaan mata. Berbeda dari TFOS DEWS II yang menekankan homeostasis air mata, ADES 2017 menekankan ketidakstabilan air mata sebagai mekanisme inti dari gejala mata kering dan/atau gangguan penglihatan. ${ }^{3}$

Menindaklanjuti konsensus pada tahun 2017, pada tahun 2020 ADES mengklasifikasikan DED menjadi tiga sesuai dengan letak lapisan air mata yang mengalami kelainan, yaitu DED akibat defisiensi aqueous, peningkatan evaporasi, dan penurunan keterbasahan permukaan mata. Tiap komponen air mata (lipid, aqueous atau secretory mucin, dan membrane-associated mucin) memengaruhi kestabilan lapisan air mata. Abnormalitas pada komponen lipid akan meningkatkan evaporasi yang kemudian menyebabkan ketidakstabilan lapisan air mata. Defisiensi aqueous, yang merupakan bentuk klasik dari mata kering, seperti yang terdapat pada sindrom Sjogren, juga menyebabkan ketidakstabilan lapisan air mata. Defisiensi membrane-associated mucin menurunkan keterbasahan kornea dan konjungtiva yang kemudian juga dapat menyebabkan ketidakstabilan lapisan air mata. ${ }^{4}$

\section{Diagnosis}

Penegakkan diagnosis diperlukan untuk membedakan antara DED, infeksi, dan alergi yang mana ketiganya memiliki gejala klinis yang serupa, tetapi penatalaksanaan yang berbeda. Anamnesis lengkap yang meliputi onset, keluhan, faktor risiko (pekerjaan, lingkungan), riwayat penyakit sistemik (Grave's disease, Sjogren syndrome, diabetes mellitus, penyakit vaskular kolagen), dan riwayat pengobatan harus ditanyakan. ${ }^{1}$ Pendekatan gejala mata kering dapat dinilai dengan menggunakan 
kuesioner Ocular Surface Disease Index (OSDI), McMonnies Questionnaire, Women's Health Study Questionnaire, atau Dry Eye-Related QoL score (DEQ). Alat ukur ini telah diuji validitas dan reliabilitasnya untuk skrining DED. ${ }^{8}$

Setelah anamnesis, pemeriksaan oftalmologi yang umumnya dilakukan antara lain tear film break up time (TBUT), tes Schirmer, pewarnaan korneakonjungtiva, pemeriksaan margo palpebra dan orifisium kelenjar Meibom. ${ }^{1,4}$ Pemeriksaan TBUT menggambarkan kestabilan lapisan air mata, dilakukan dengan menggunakan zat pewarna fluoresein $1 \%$. Jumlah zat fluoresein yang ditetes sekitar 1-2 L, pemberian dapat menggunakan pipet atau kertas strip fluoresein. Setelah itu, pasien diminta untuk mengedipkan mata sebanyak tiga kali untuk memastikan zat warna bercampur dengan air mata secara adekuat. Waktu interval yang dibutuhkan antara kedipan terakhir sampai munculnya bercak gelap pada kornea diukur menggunakan stopwatch. Waktu kurang dari 10 detik menunjukkan bahwa pasien memiliki mata kering. ${ }^{9}$ Pemeriksaan sekresi air mata dapat dinilai dengan tes Schirmer I (tanpa anestesi) dan tear film meniscus height (meniscometry). Tes Schirmer I yang kurang dari $5 \mathrm{~mm}$ dalam 5 menit dan tear film meniscus height $<0,25 \mathrm{~mm}$ menggambarkan penurunan sekresi air mata yang ditemui pada penyakit mata kering tipe ADDE.,

Pemeriksaan palpebra dan margo palpebra meliputi penilaian adanya entropion, ektropion, lagoftalmos, paralisis N.VII, obstruksi orifisium kelenjar Meibom. Frekuensi berkedip juga perlu diperhatikan karena berkedip merupakan mekanisme mata untuk mendistribusikan air mata ke seluruh permukaan mata sehingga jika terjadi penurunan frekuensi berkedip, yang sering terjadi pada saat membaca atau menggunakan komputer, akan terjadi peningkatan evaporasi air mata yang berujung pada penyakit mata kering tipe EDE. ${ }^{1,4}$

Pewarnaan kornea dan konjungtiva dilakukan dengan slit lamp biomicroscopy. Jenis pewarnaan yang umum dipakai adalah fluorescein, lissamine green, dan rose bengal. Salah satu terobosan tentang pendekatan diagnosis DED dilaporkan

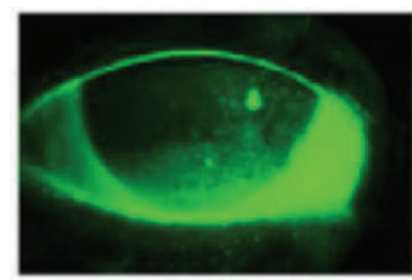

Area break

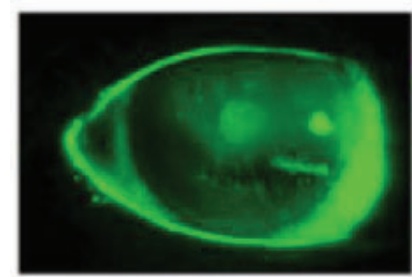

Line break

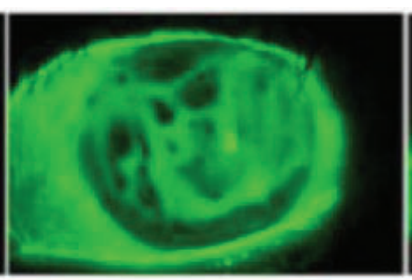

Spot break

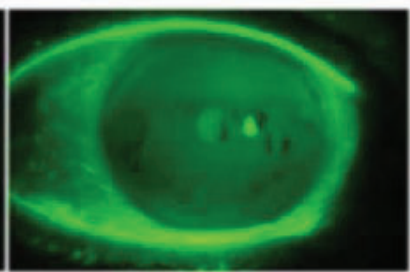

Dimple break

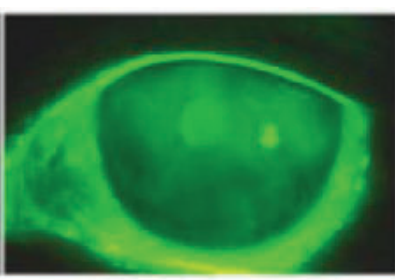

Random break

Gambar 1. Fluorescein breakup pattern

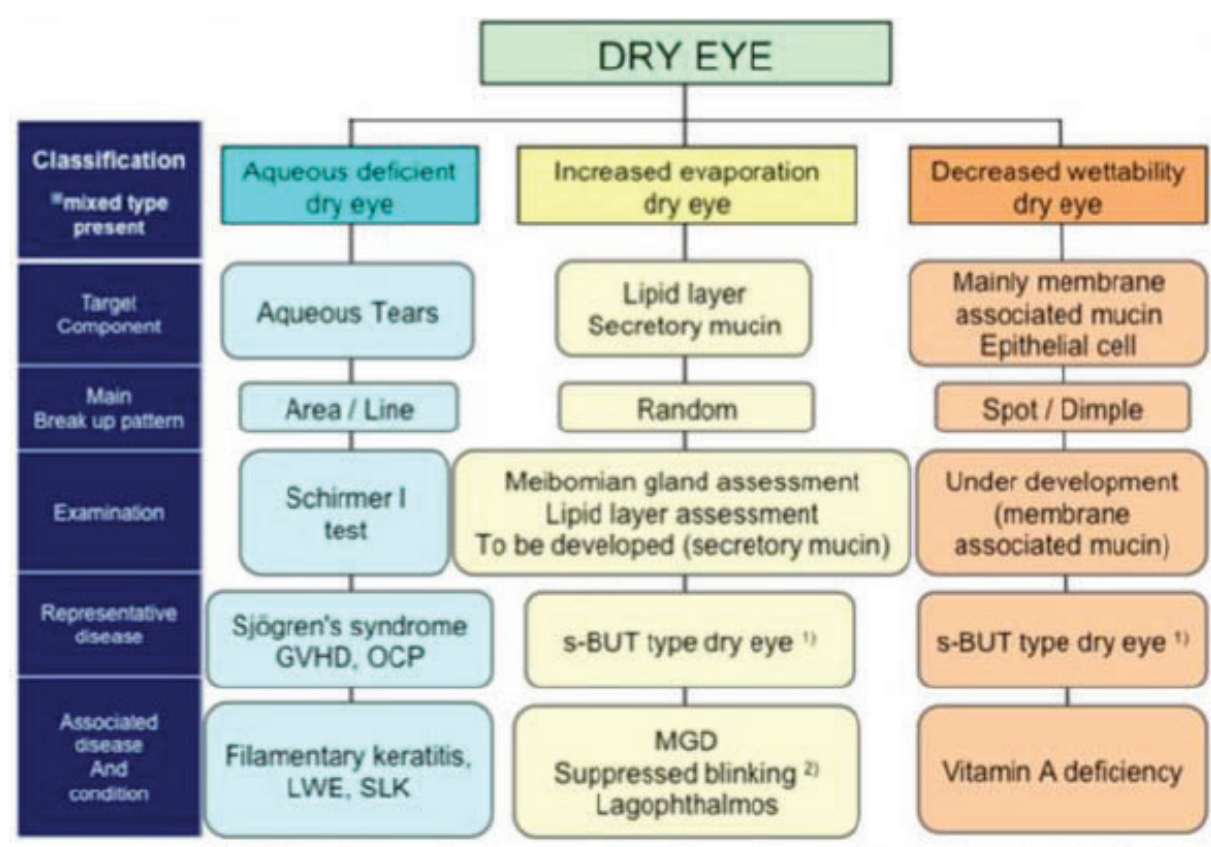

"s-BUT type dry eye: dry eye symptom/normal tear volume and no/slight staining "VDT related.

Gambar 2. Klasifikasi penyakit mata kering menurut ADES.

oleh Yokoi et al. yang menyebutkan bahwa fluorescein breakup pattern (FBUP) dapat menentukan klasifikasi DED. ${ }^{10}$ Tear film breakup dapat timbul akibat peningkatan evaporasi, penurunan volume aqueous air mata, dan penurunan keterbasahan permukaan kornea. Detail gambaran tear film breakup pada tiap tipe DED dapat dilihat pada Gambar 1. Jika DED disebabkan oleh defisiensi aqueous, maka pola yang dominan muncul adalah line atau area break. Jika DED disebabkan peningkatan evaporasi, pola yang muncul adalah random break. Sementara itu, DED akibat penurunan keterbasahan akan memberikan gambaran pola berupa spot atau dimple break..$^{4,10}$

Berdasarkan konsensus ADES 2017, diagnosis mata kering dapat ditegakkan dengan gejala klinis (menggunakan kuesioner) yang disertai dengan ketidakstabilan lapisan air mata 


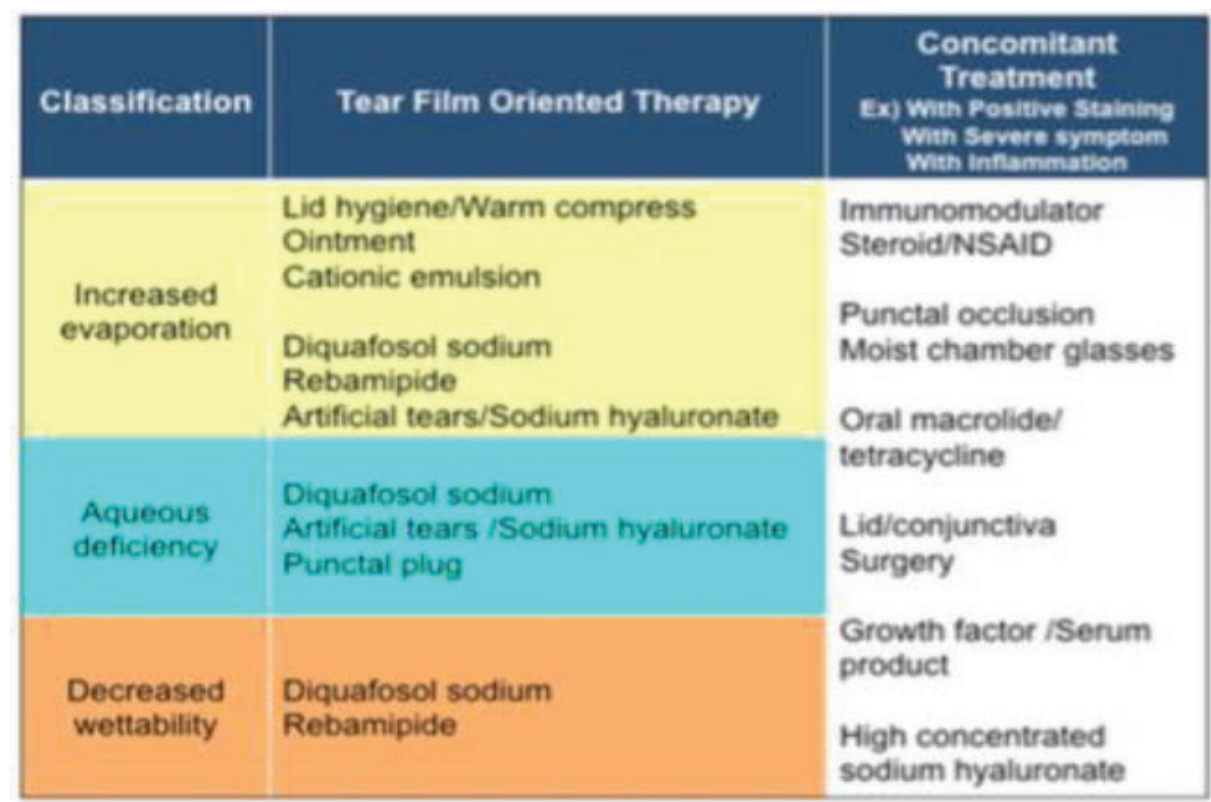

Gambar 3. Tear Film Oriented Therapy (TFOT).

(menggunakan pemeriksaan TBUT). ${ }^{3}$ Pada skema (Gambar 2) yang ditampilkan di laporan ADES tahun 2020, dijabarkan jenis-jenis pemeriksaan yang dilakukan berdasarkan dari klasifikasi DED. DED tipe defisiensi aqueous dapat didiagnosis dengan pemeriksaan Schirmer $I$ atau meniscometry. Pada DED tipe defisiensi lipid, karena erat kaitannya dengan disfungsi kelenjar Meibom, pemeriksaan manual kelopak mata dapat membantu diagnosis. Selain itu, lipid layer inferometry, walau jarang digunakan, dapat digunakan untuk mengevaluasi penurunan ketebalan lapisan lipid pada pasien DED. ${ }^{4}$

\section{Tatalaksana}

ADES telah mengusung klasifikasi DED berdasarkan lapisan air mata yang mengalami kelainan. Klasifikasi ini kemudian menjadi dasar penting untuk konsep penatalaksanaan DED yang kemudian disebut dengan Tear Film Oriented Therapy (TFOT) (Gambar 3).

Jika DED disebabkan oleh defisiensi mucin, pasien sebaiknya diberikan mucin secretatogue seperti tetes mata diquafosol atau rebamipide. ${ }^{3,4,11}$ Diquafosol merupakan P2Y2 reseptor agonis yang berfungsi meningkatkan sekresi aqueous dan mucin, sedangkan rebamipide merupakan derivat quinolinone yang berfungsi meningkatkan komponen mucin pada lapisan air mata. Pada beberapa penelitian, diquafosol dan rebamipide terbukti dapat meningkatkan TBUT dan memperbaiki staining kornea dan konjungtiva. ${ }^{4,11-14}$

Jika lapisan aqueous yang mengalami kelainan, seperti pada sindrom Sjogren maupun non-Sjogren, maka terapi berfokus pada peningkatan volume air mata dengan pemberian artificial tears, asam hyaluronat, diquafosol, atau oklusi puncta. Artificial tears dan asam hyaluronat merupakan terapi inisial yang umum dipilih, namun keduanya memiliki durasi yang singkat pada permukaan mata, yaitu sekitar 3-5 menit. Diquafosol memiliki efikasi yang lebih baik dibandingkan dengan artificial tears dan asam hyaluronat sehingga saat ini menjadi terapi pilihan pertama. ${ }^{13-16}$ Oklusi puncta tidak hanya meningkatkan komponen aqueous, tetapi juga komponen lipid dan mucin. Kombinasi oklusi puncta dengan diquafosol memberikan perbaikan jangka panjang pada ADDE berat..$^{1,4,12}$

Pemberian anti-inflamasi dipercaya dapat meningkatkan stabilitas lapisan air mata. Tetes mata siklosporin A merupakan imunosupresan yang berfungsi menurunkan aktivasi sel $\mathrm{T}$ melalui IL-2. Pemberian siklosporin A $0,05 \%$ sebanyak 2 kali per hari dapat memperbaiki keratopati, meningkatkan hasil tes Schirmer dan mengurangi keluhan subjektif pasien. Lifitegrast juga merupakan modalitas baru yang sudah melalui fase 3 uji klinis. Obat ini berfungsi menghambat interaksi antara ICAM-1 dan LFA-1 yang berpengaruh pada aktivasi dan migrasi sel T. Pemberian kortikosteroid topikal seperti fluorometholone selama 2-4 minggu terbukti mengurangi keluhan subjektif pasien DED dan memperbaiki staining kornea. ${ }^{1,412}$

Jika kelainan ada pada lapisan lipid, seperti yang sering ditemukan pada disfungsi kelenjar Meibom, maka tatalaksana mengacu pada algoritma terapi disfungsi kelenjar Meibom, yaitu kompres hangat, lid hygiene, artificial tears, antibiotik sistemik/topikal (golongan tetrasiklin atau makrolid), dan suplementasi asam lemak omega-3 (yang terdapat pada minyak ikan).,34

\section{SIMPULAN}

DED diklasifikasikan menjadi tiga tipe berdasarkan lapisan air mata yang mengalami kelainan, yaitu defisiensi aqueous, peningkatan evaporasi, dan penurunan keterbasahan kornea, dan konjungtiva. Pendekatan diagnosis tipe DED dapat dilakukan dengan melihat fluorescein breakup pattern (FBUP) di mana pada defisiensi aqueous pola yang dominan adalah line atau area break, pada peningkatan evaporasi akan menunjukkan pola random break, dan pada penurunan keterbasahan akan menunjukkan pola spot atau dimple break.

Ketiga klasifikasi ini kemudian yang menjadi dasar penting untuk konsep penatalaksanaan DED yang disebut dengan Tear Film Oriented Therapy (TFOT). Jika DED disebabkan oleh defisiensi mucin, pasien sebaiknya diberikan mucin secretatogue seperti tetes mata diquafosol atau rebamipide. Jika lapisan aqueous yang mengalami kelainan, seperti pada sindroma Sjogren maupun non-Sjogren, maka terapi berfokus pada peningkatan volume air mata dengan pemberian artificial tears, asam hyaluronat, diquafosol, atau oklusi puncta. Jika kelainan ada pada lapisan lipid, seperti yang sering ditemukan pada disfungsi kelenjar Meibom, maka tatalaksana mengacu pada algoritma terapi disfungsi kelenjar Meibom, yaitu kompres hangat, lid hygiene, artificial tears, antibiotik sistemik/topikal, dan suplementasi asam 
lemak omega-3.

\section{KONFLIK KEPENTINGAN}

Penulis menyatakan tidak terdapat konflik kepentingan terkait publikasi dari artikel ini.

\section{PENDANAAN}

Penelitian ini tidak mendapat dana hibah dari pemerintah ataupun lembaga swasta lainnya.

\section{KONTRIBUSI PENULIS}

Penulis berkontribusi terhadap penelitian ini baik dari perencanaan hingga interpretasi dan penyusunan naskah publikasi.

\section{DAFTAR PUSTAKA}

1. Messmer EM. The pathophysiology, diagnosis, and treatment of dry eye disease. Dtsch Arztebl Int. 2015;112(5):71-82. doi:10.3238/ arztebl.2015.0071.

2. Craig JP, Nichols KK, Akpek EK, et al. TFOS DEWS II Definition and Classification Report. The Ocular Surface. 2017 Jul;15(3):276-283. DOI: 10.1016/j.jtos.2017.05.008.

3. Tsubota K, Yokoi N, Shimazaki J, et al. New Perspectives on Dry Eye Definition and Diagnosis: A Consensus Report by the Asia Dry Eye Society. Ocul Surf. 2017;15(1):65-76. doi:10.1016/j.jtos.2016.09.003.
4. Tsubota K, Yokoi N, Watanabe $\mathrm{H}$, et al. A New Perspective on Dry Eye Classification: Proposal by the Asia Dry Eye Society [published correction appears in Eye Contact Lens. 2020 Sep;46(5):e39]. Eye Contact Lens. 2020;46 Suppl 1(1):S2-S13. doi:10.1097/ ICL.0000000000000643.

5. Stapleton F, Alves M, Bunya VY, et al. TFOS DEWS II Epidemiology Report. Ocul Surf. 2017;15(3):334-365. doi:10.1016/j. jtos.2017.05.003.

6. Farrand KF, Fridman M, Stillman IÖ, Schaumberg DA. Prevalence of Diagnosed Dry Eye Disease in the United States Among Adults Aged 18 Years and Older. Am J Ophthalmol. 2017;182:90-98. doi:10.1016/j.ajo.2017.06.033

7. Yokoi N, Uchino M, Uchino Y, et al. Importance of tear film instability in dry eye disease in office workers using visual display terminals: the Osaka study. Am J Ophthalmol. 2015;159(4):748-754. doi:10.1016/j.ajo.2014.12.019.

8. Wolffsohn JS, Arita R, Chalmers R, et al. TFOS DEWS II Diagnostic Methodology report. Ocul Surf. 2017;15(3):539-574. doi:10.1016/j. jtos.2017.05.001.

9. Tsubota K. Short Tear Film Breakup TimeType Dry Eye. Invest Ophthalmol Vis Sci. 2018;59(14):DES64-DES70. doi:10.1167/ iovs.17-23746.

10. Yokoi N, Georgiev GA, Kato $\mathrm{H}$, et al. Classification of Fluorescein Breakup Patterns: A Novel Method of Differential Diagnosis for Dry Eye. Am J Ophthalmol. 2017;180:72-85. doi:10.1016/j.ajo.2017.05.022.

11. Jones L, Downie LE, Korb D, et al. TFOS DEWS II Management and Therapy Report. Ocul Surf. 2017;15(3):575-628. doi:10.1016/j. jtos.2017.05.006.
12. Holland EJ, Darvish M, Nichols KK, Jones L, Karpecki PM. Efficacy of topical ophthalmic drugs in the treatment of dry eye disease: A systematic literature review. Ocul Surf. 2019;17(3):412-423. doi:10.1016/j. jtos.2019.02.012.

13. Kaido M, Kawashima M, Shigeno Y, Yamada Y, Tsubota K. Randomized Controlled Study to Investigate the Effect of Topical Diquafosol Tetrasodium on Corneal Sensitivity in Short Tear Break-Up Time Dry Eye. Adv Ther. 2018;35(5):697-706. doi:10.1007/s12325-0180685-1.

14. Amano S, Inoue K. Effect of topical 3\% diquafosol sodium on eyes with dry eye disease and meibomian gland dysfunction. Clin Ophthalmol. 2017;11:1677-1682. Published 2017 Sep 14. doi:10.2147/OPTH.S148167.

15. Utsunomiya T, Kawahara A, Hanada K, Yoshida A. Effects of Diquafosol Ophthalmic Solution on Quality of Life in Dry Eye Assessed Using the Dry Eye-Related Quality-of-Life Score Questionnaire: Effectiveness in Patients While Reading and Using Visual Display Terminals. Cornea. 2017;36(8):908-914.

16. Mun Y, Kwon JW, Oh JY. Therapeutic effects of $3 \%$ diquafosol ophthalmic solution in patients with short tear film break-up time-type dry eye disease. BMC Ophthalmol. 2018;18(1):237. Published 2018 Sep 5. doi:10.1186/s12886-0180910-3.

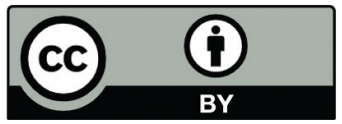

This work is licensed under a Creative Commons Attribution 